\title{
ISOLATION AND IDENTIFICATION OF MICROBIAL FAUNA IN UTI PATIENTS
}

\author{
Muhammad Ilyas, Saffora Riaz*, Ali Hassan \\ Combined Military Hospital Lahore/National University of Medical Sciences (NUMS) Pakistan, *Lahore College for Women University, Lahore Pakistan
}

\begin{abstract}
Urinary tract infection caused by bacteria leads to inflammation. It is an important infection which can cause a highly morbidity rates in both males and females. The aim of the present study was determine the percentage prevalence of the UTI among the general population and the percentage of the bacterial isolates in the Urine samples. Among 150 samples bacterial isolates were obtained which included Escherichia coli, Klebsiella pneumonia, Proteus vulgaris, Pseudomonas aeruginosa. The highest prevalence of specific bacteria was found to be Escherichia coli recorded among all the UTI patients to be (55.55\%) the least percentage among the bacteria were Klebsiella pneumonia, Proteus vulgaris, Pseudomonas aeruginosa and Enterobacter aerogenes which recorded $16.66 \%, 5.55 \%, 11.11 \%$ and $11.11 \%$ respectively. Results of the study showed that of females had UTI more than the males.
\end{abstract}

Keywords: Bacteria, Escherichia coli, UTI.

How to Cite This Article: Liyas M, Riaz S, Hassan S. Isolation and Identification of Microbial Fauna in UTI Patients. Pak Armed Forces Med J 2021; 71(6): 2242-2244. Doi: https://doi.org/10.51253/pafmj.v71i6.6585

This is an Open Access article distributed under the terms of the Creative Commons Attribution License (https://creativecommons.org/licenses/by-nc/4.0/), which permits unrestricted use, distribution, and reproduction in any medium, provided the original work is properly cited.

\section{INTRODUCTION}

Urinary tract infections (UTIs) one of the most contagious and infectious disease caused by the abnormal growth of pathogens are the inflammatory disorders of the urinary tract. ${ }^{1,2}$ Pyelonephritis and cystitisencompass ranges of morbidity in urinary tract infections are characterized by the existence of microorganism in urinary tract. 3,4 When it affects the lower urinary tract cause dysuria and lower abdominal pain (LAP) and may result in permanent scarring of the kidney, ureters, bladder and urethra and symptoms are frequent urination, and feeling the need to urinate despite having an empty bladder. ${ }^{5}$ Renal scarring may lead to complications in adulthood including hypertension, proteinuria, renal damage and even chronic renal failure, which requires dialysis treatment. ${ }^{6}$ UTIs depend the clinical manifestations of the etiologic organisms, the portion of the urinary tract involved, the severity of the infection and may be asymptomatic, acute, chronic, and complicated or uncomplicated. Both asymptomatic and symptomatic UTIs pose a serious threat to public health care, hence differentiated into lower UTIs (cystitis) and upper UTIs (pyelonephritis). ${ }^{7,8}$

Asymptomatic bacteriuria is a condition in which the bacteria present in the urine but symptoms do not result. In Uncomplicated UTI patient have no severe complications and history of anatomical or functional

Correspondence: Dr Saffora Riaz, Department of Zoology, Lahore College for Women University Lahore-Pakistan

Received: 17 Apr 2021; revision received: 19 Apr 2021; accepted: 19 Apr 2021 abnormality of the urinary tract, but complicated UTI include immunosuppressed patients and patients with comorbidities of the urinary tract. Urinary Tract Infections are caused by both Gram-negative and Grampositive bacteria, as well as by certain fungi the most common causative agent for both uncomplicated and complicated Urinary Tract Infections are uropathogenic Escherichia coli. ${ }^{9}$

The epidemiology and the characteristics of urinary tract infections in children, frequency of urinary tract infection causing agents in pregnant women and their antimicrobial susceptibility patterns was studied. ${ }^{10}$

\section{METHODOLOGY}

\section{Demographic Data}

Demographic data i.e,. name of the patient, age, gender, locality and duration of the infection was collected on the designed questionnaire.

\section{Urine Specimen Collection}

A clean catch midstream urine samples were collected in sterile clean leak proof bottles from each patient. Urine samples were collected from both male and female, of all age groups from $\mathrm{CMH}$ Lahore.

\section{Physical Examination of Urine}

Urine specimen $(n=150)$ were collected from $\mathrm{CMH}$ Lahore. The physical parameters of collected urine specimens were analyzed such as the volume, $\mathrm{pH}$, and colour, pus cells, RBC's, Protein, Epithelial cells and blood by Urine test strips (Healthy Wiser, Lot no. 031-101,USA). 


\section{RESULTS}

\section{Demographic Data of UTI Patients}

Total 150 patients of UTI of either gender (both male and female) between age group of 12-80 years were studied (Table-I). Demographic features of Urinary Tract Infected patients are shown in. Data shows the highest prevalence of UTI is found in the age group of 51-60 in females and in males with age group of 21-30.

\section{Urinalysis of Urine Samples of UTI Patients}

Urine specimen $(n=150)$ were collected from $\mathrm{CMH}$ Lahore. The Physical parameters of all the urine samples were determined. Parameters such as $\mathrm{pH}$, Color, RBCs, epithelial cells and pus cells were noted. patients in the range of $0-4$ and $14 \%$ concentration of epithelial cells present in the range of $0-1,65 \%$ in $1-2$, $21 \%$ in $2-3$ and $2 \%$ concentration of epithelial cells present in the range of 3-4 as shown in Figure.

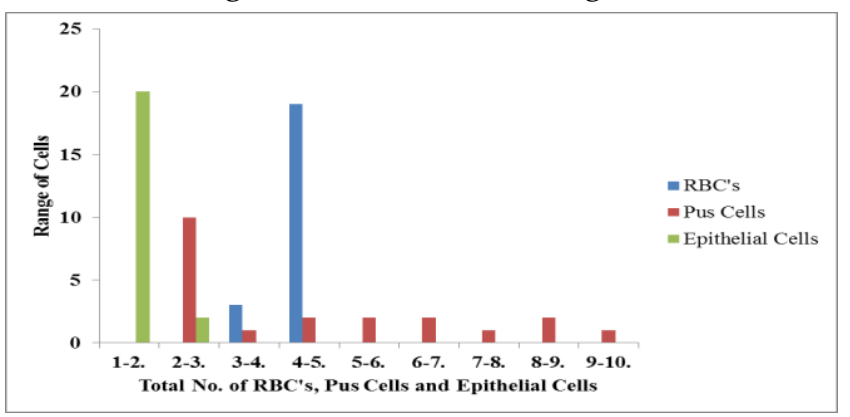

Figure: The numbers of RBC's, Pus cells and epithelial cells in the urine samples of UTI patients.

Table-I: UTI infection among different age group of the population visited CMH Lahore.

\begin{tabular}{|c|c|c|c|c|c|c|c|c|c|}
\hline \multirow{2}{*}{$\begin{array}{l}\text { Age Groups } \\
\text { (Years) }\end{array}$} & \multirow{2}{*}{$\begin{array}{c}\text { No. of UTI } \\
\text { Males, } n=55\end{array}$} & \multirow{2}{*}{$\begin{array}{c}\text { No. of UTI } \\
\text { Females, } n=95\end{array}$} & \multicolumn{2}{|c|}{ Mean Value } & \multicolumn{2}{|c|}{ S.D \pm S.E } & \multirow{2}{*}{ df } & \multirow{2}{*}{$\mathbf{F}$} & \multirow{2}{*}{ Sig. } \\
\hline & & & Male & Female & Male & Female & & & \\
\hline $12-20$ & $6(4 \%)$ & $8(5.3 \%)$ & \multirow{7}{*}{4.7} & \multirow{7}{*}{4.3} & \multirow{7}{*}{$2.006 \pm 0.27$} & \multirow{7}{*}{$1.88 \pm 0.19$} & \multirow{7}{*}{1} & \multirow{7}{*}{1.018} & \multirow{7}{*}{0.315} \\
\hline $21-30$ & $4(2.6 \%)$ & $11(7.3 \%)$ & & & & & & & \\
\hline $31-40$ & $6(4 \%)$ & $14(9.3 \%)$ & & & & & & & \\
\hline $41-50$ & $5(3.3 \%)$ & $12(8 \%)$ & & & & & & & \\
\hline $51-60$ & $9(6 \%)$ & $19(12.6 \%)$ & & & & & & & \\
\hline $61-70$ & $13(8.6 \%)$ & $16(10.6 \%)$ & & & & & & & \\
\hline $71-80$ & $12(8 \%)$ & $15(10 \%)$ & & & & & & & \\
\hline
\end{tabular}

\section{DISCUSSION}

In this study prevalence of UTI was much higher in age group of 21-30 in males and in the age group 5130 in females. Although the infection rate was higher in married females patients as compared to unmarried females which is in accordance with the previous study 10E. coli was observed as the most common etiologic agent of UTIalone account for $70-90 \%$ of the UTI infections. ${ }^{11}$ UTIs caused by antibiotic resistant and multiple drug resistant bacteria have been increased in recent times. In the present study we analyzed their antibiotic sensitivity pattern determined by Antibiotic susceptibility test.

Similar results showed that females had UTI more than the males which accounted for 55.23\% compared to $44.79 \%$ and results of this study showed that the rate of girls with UTI were higher $62.74 \%$ in comparison with boys $37.25 \% .{ }^{12-14}$

Through results of urinalysis the percentage population of $77 \%$ proteins and $60 \%$ blood is detected in urine samples of UTI patients and the percentage popula-tion of pus cells detected in urine samples of UTI patients in $0-20$ range. ${ }^{15-17}$ Percentage population of epithelial cells also detected in urine samples of UTI
About $95 \%$ of urinary tract infection caused by many types of bacteria. 18,19 The results of the current study because the prevalence in the present study groups of various bacteria was $60.78 \%$, because the reasons for the emergence of the outcome of these few due to an error occurred during the sampling, may be an error occurred during the preparation of culture media, or media inappropriate appearance of sort's isolation of different bacteria. Distribution of isolated bacteria among study groups was shown in Table-II. The highest prevalence of specific bacteria was found to be Escherichia coli recorded among all the paediatric UTI to be $(55.55 \%)$ the least percentage among the bacteria were Klebsiella pneumonia, Proteus vulgaris, Pseudomonas aeruginosa and Enterobacter aerogenes which recorded $16.66 \%, 5.55 \%, 11.11 \%$ and $11.11 \%$ respectively.

Table-II: Distribution of isolated bacteria among study groups.

\begin{tabular}{l|c}
\hline Isolated Bacteria & $\begin{array}{c}\text { Bacterial isolates in } \\
\text { positive UTI cases (\%) }\end{array}$ \\
\hline Escherichia coli & $55.55 \%$ \\
\hline Klebsiella pneumonia & $16.66 \%$ \\
\hline Proteus vulgaris & $5.55 \%$ \\
\hline Pseudomonas aeruginosa & $11.11 \%$ \\
\hline Enterobacter aerogenes & $11.11 \%$ \\
\hline
\end{tabular}


The highest prevalence of specific bacteria was found to be E.coli recorded among all the pediatric UTI to be $(35 \%)$ the least percentage among the bacteria were Klebsiella pneumonia, Proteus mirabilis, Pseudomonas aeruginosa, Staphylococcus aureus, Staphylococcus epidermidis which recorded 30\%, 7.5\%,5\%, 15\% and $7.5 \%$ respectively. ${ }^{20}$

\section{CONCLUSION}

The appropriate treatment for UTI has been a subject of recent research. The study found that $E$. coli is the principal etiological agent of UTI. The occurrence of UTI is significantly related to age in female patients, that is, the disease incidence increases with increasing age and vice versa for male patients. Identification of the causative organisms and its susceptibility to antimicrobials is important, so that proper drug is chosen to treat the patient in early stages of UTI. It is therefore recommended that routine microbiological analysis and antibiotic sensitivity test of mid-stream urine samples of patients be carried out before the treatment in the management of UTIs. Over and above for prevention of UTIs implementation of strict infection control guidelines, effective hand washing and judicious use of antimicrobials is mandatory which goes a long way to cope up, with the emergence of drug resistance among uropathogens.

\section{Conflict of Interest: None.}

\section{Authors' Contribution}

MI: Conception of design, SR: Analysis interpretation of data and, Drafting the article, AH: Acquition of data.

\section{REFERENCES}

1. Bano K, Khan J, Begum RH, Munir S, Akbar N, Ansari JA, et al. Patterns of antibiotic sensitivity of bacterial pathogens among urinary tract infections (UTI) patients in a Pakistani population. Afr J Microbiol Res 2012; 6(2): 414-420.

2. Boye A, Siakwa PM, Boampong JN, Koffuor GA, Ephraim RKD, Amoateng P, et al. Asymptomatic urinary tract infections in pregnant women attending antenatal clinic in Cape Coast, Ghana. E3 J Med Res 2012; 1(6): 74-83.

3. Camacho V, Estorch M, Fraga G, Mena E, Fuertes J, Hernandez $\mathrm{M}$, et al. DMSA study performed during febrile urinary tract infection: a predictor of patient outcome. Eur J Nuclear Med And Molecul Imag 2004; 31(6): 862-866.

4. Foxman B. Urinary tract infection syndromes: occurrence, recurrence, bacteriology, risk factors, and disease burden. Infectious disease clinics of North America, 2014; 28(1): 1-13.

5. Hooton TM. Uncomplicated urinary tract infection. New Engl J Med 2012; 366: 1028-1037.
6. Kulkarni R, Dhakal BK, Slechta ES. Roles of putative type II secretion and type IV pilus systems in the virulence of uropathogenic Escherichia Coli PLoS One 2009; 4(3): 47-52.

7. Lane DR, Takhar SS. Diagnosis and management of urinary tract infection and pyelonephritis.Emergency Medicine Clinics of North America, 2011; 29(3): 539-552.

8. Lau SH, Reddy S, Cheesbrough J, Bolton FJ, Willshaw G, Cheasty $\mathrm{T}$, et al. Major uropathogenic Escherichia coli strain isolated in the northwest of England identified by multilocus sequence typing. J Clinical Microbiol 2008; 46(3): 1076-1080.

9. Levison ME, Kaye D. Treatment of complicated urinary tract infections with an emphasis on drug-resistant gram-negative uropathogens. Current Infect Disease Report 2013; 15(2): 109-115.

10. López-Banda DA, Carrillo-Casas EM, Leyva-Leyva M, OrozcoHoyuela G, Manjarrez-Hernández ÁH, Arroyo-Escalante S, et al. Identification of virulence factors genes in Escherichia coli isolates from women with urinary tract infection in Mexico. Bio Med Res Inter 2014; 14(3): 1-10.

11. Nicolle LE. Uncomplicated urinary tract infection in adults including uncomplicated pyelonephritis. Urol Clin North Am 2008; 35(1): 1-12.

12. Olowe O. Ojo-Johnson B, Makanjuola O, Olowe R, Mabayoje V. Detection of bacteriuria among human immunodeficiency virus seropositive individuals in Osogbo, south-western Nigeria. Europ J Microbiol Immunol 2015; 5(1): 126-130.

13. Prakash, D. and Saxena, R. Distribution and antimicrobial susceptibility pattern of bacterial pathogens causing urinary tract infection in Urban Community of Meerut City, India. ISRN Microbiol 2013; 13(5): 13-18.

14. Saha S, Nayak S, Bhattacharyya I, Saha S, Mandal, A, Chakraborty $\mathrm{S}$, et al. Understanding the patterns of antibiotic susceptibility of bacteria causing urinary tract infection in West Bengal, India. Frontiers Microbiol 2014; 5(1): 463-469.

15. Sarwar MI, Sarwar I, Hussain MS, Sherwani SK, Hakeem A, Kazmi SU. Frequency of urinary tract infection causing agents in pregnant women and their antimicrobial susceptibility profile. Pak J Biochem Mol Biol 2013; 46(3-4): 107-110.

16. Shah PS, Cannon JP, Sullivan CL. Controlling antimicrobial use and decreasing microbiological laboratory tests for urinary tract infections in spinal-cord-injury patients with chronic indwelling catheters. Am J Health Syst Pharm, 2005; 62(1): 74-77.

17. Sood S, Gupta R. Antibiotic resistance pattern of community acquired uropathogens at a tertiary care hospital in Jaipur, Rajasthan. Indian journal of community medicine: official Public Ind Assoc Preven Social Med 2012; 37(1): 39-45.

18. Stamm WE, Norrby SR. Urinary tract infections: disease panorama and challenges. J Infec Diseas 2001; 183(1): 1-4.

19. Tan CW, Chlebicki MP. Urinary tract infections in adults. Singapore Med J 2016; 57(9): 485-488.

20. Shahab WN, Ali CIAD, Salih SM. Isolation and Identification of bacteria causing urinary tract infections in children in Kirkuk city. Tikrit J Pure Sci 2017; 22(2): 8-12. 